\title{
Diversity and distribution of tick species infesting goats with two new host records from Sri Lanka
}

\author{
G.C.P. Diyes and R.S. Rajakaruna* \\ Department of Zoology, Faculty of Science, University of Peradeniya, Peradeniya.
}

Revised: 16 November 2014; Accepted: 22 January 2015

\begin{abstract}
An island-wide study on ticks that infest the domestic goat, Capra aegagrus hircus was carried out from June 2011 to May 2013. A total of 2,628 ticks were collected in 22 districts within the three agro-climatic zones in Sri Lanka from 740 goats belonging to various breeds. Eight species of ticks belonging to the two genera Haemaphysalis and Rhipicephalus (Family Ixodidae) including Haemaphysalis bispinosa, H. intermedia, $H$. cuspidata, Rhipicephalus sanguineus, R. haemaphysaloides, R. turanicus, R. (Boophilus) annulatus and R. (Boophilus) microplus were recorded. The most common species in the overall collection were $H$. intermedia $(44.0 \%)$ and $H$. bispinosa (43.8\%). Haemaphysalis bispinosa was the dominant species in the Wet and Intermediate Zones, except in a few locations. In these exceptions $H$. intermedia was the dominant species, which was also the most abundant species found in the Dry Zone. Haemaphysalis bispinosa and $R$. sanguineus were restricted only to the Wet and Intermediate Zones. Of the eight tick species found, the two species, $R$. turanicus and $R$. microplus were new host records from Sri Lanka. More adult stages $(70.8 \%)$ were found in goats, where nymphs and larvae formed 25.9 and $3.3 \%$, respectively. All three stages of the dominant tick species were found on goats except for immature stages of $R$. haemaphysaloides and $R$. sanguineus. Most ticks preferred the anterior side of the body with one exception, $R$. microplus, which was more attracted to the posterior side of the host. This study reports the tick species infesting goats with zoonotic potential and also known vectors of many tick borne diseases of human and livestock.
\end{abstract}

Keywords: Agro-climatic zones, attachment sites, goat ticks, Haemaphysalis, Rhiphicephalus, Sri Lanka.

\section{INTRODUCTION}

Ticks damage the host in two ways; directly by tick bites and indirectly by disease transmission. Failure to control tick infestations in livestock may result in reduced live weight, reduced milk production and even death in young animals (Ghosh et al., 2006; Rony et al., 2010). Knowledge on the diversity of ticks, geographic distribution, infections they carry and their zoonotic potential is important for the prevention and effective control of ticks and tick borne diseases. Wild animals can maintain and reintroduce ticks and tick borne diseases to livestock via alternative hosts. Goats are known to act as alternative hosts for many tick species when a suitable host (wild or domestic) is not available (Nyangiwe \& Horak, 2007). For example, Rhipicephalus microplus usually infests cattle but can successfully complete its life cycle on goats (Daemon et al., 1998; Nyangiwe \& Horak, 2007). Wild animals can transmit tick borne viral infections like flaviviruses, bacterial agents as Anaplasma, Borrelia, Rickettsia and protozoans as Babesia, Theileria to livestock (Uilenberg, 1999; Jongejan \& Uilenberg, 2004). These infections have been frequently reported in livestock in neighbouring countries including India, Bangladesh and Pakistan (Estrada-pena \& Jongejan, 1999; Ghosh et al., 2007). In these countries Haemaphysalis bispinosa, Rhipicephalus sanguineus and $R$. microplus have been identified as possible vectors for Babesia motasi, B. ovis and Theileria ovis infections to goats (Ghosh et al., 2007). Among tick borne infections a high prevalence of Babesia bigemina, B. bovis, T. annulata and $T$. orientalis have been recorded in cattle from many parts of the world including Sri Lanka (Brown, 1990; Bock et al., 2004; Aktas et al., 2006; Sivakumar et al., 2012). Moreover, many rickettsial infections have also been reported in humans in Sri Lanka (Kularatne et al., 2003; Premaratna et al., 2008), which are suspected as tick borne infections. The reservoir and the vector of these infections in Sri Lanka are largely unknown. 
Since the ticks, pathogens and their specific hosts are linked (Jongejan \& Uilenberg, 2004; Petney et al., 2011), information about the diversity and distribution of tick fauna is very important to understand the zoonotic potential of tick borne diseases (Leger et al., 2013). Three genera of ticks, namely, Haemaphysalis, Rhipicephalus and Hyalomma include most of the tick species that infest goats and sheep in many parts of the world (Al-Khalifa et al., 2007; Sajid et al., 2008; Matos et al., 2009, Iqbal et al., 2014). In addition to the above genera Dermacentor, Amblyomma and Ixodes have also been reported infesting goats (Latha et al., 2004; Ghosh et al., 2007; Yin \& Luo, 2007). Studies on the tick fauna of Sri Lanka are scanty. Seneviratne (1965) listed seven tick species belonging to the three genera Haemaphysalis, Rhipicephalus and Hyalomma infesting goats. A subsequent survey carried out much later in a State livestock farm in the Dry Zone of Sri Lanka recorded five tick species belonging to the genera Haemaphysalis and Rhipicephalus infesting goats (Halim et al., 1983). More recently, Liyanarachchi et al. (2013) reported eight species of ticks from farm goats.

Goats (Capra aegagrus hircus) are important in the livestock production system in Sri Lanka. Owing to their high fertility, short generation time and adaptability to arid and semiarid conditions, goats are popular livestock animals in many rural communities. The goat and sheep population in the country has been recorded as 393,000 with 62,928 goat farms in the country (Department of Animal Production and Health, 2012). Goat distribution is mostly linked with the socio-cultural pattern in the country, and are mainly reared for meat and rarely for their milk. In Sri Lanka goat farming is mainly concentrated in the Dry and Intermediate Zones where about $75 \%$ of the goat population is distributed (Department of Animal Production and Health, 2012). Rest of the goat population is distributed in pockets in the Wet Zone, with herd sizes ranging from 5 or less than 5 to 150 , and are mainly confined to smallholder farmers. In Sri Lanka there are five goat breeds commonly found, namely, Boer, Beetal, Kottukachchiya, Jamunapari, Sannan and their cross breeds. Of these, Sannan is the common goat breed in the Wet Zone of Sri Lanka (personal observation). All the goats sampled for the present study were reared as free grazers in almost all the areas except in a few localities in the Wet Zone, where cut grasses were provided during the rainy season. The objective of this study is to determine the diversity and island-wide distribution of goat ticks of Sri Lanka, which will be useful for controlling ticks and tick borne diseases in livestock because only some tick species act as vectors of tick borne infections.

\section{METHODS AND MATERIALS}

\section{Study area}

The study was conducted in three agro-climatic zones of Sri Lanka $\left(7.00^{\circ} \mathrm{N}, 81.00^{\circ} \mathrm{E}\right)$ in the Dry, Wet and Intermediate Zones. The Dry Zone covers the northern and eastern parts of the country, while the Wet Zone is in the south-western parts with central hills and the intermediate zone being the frontier between the above two zones. The Wet Zone receives a high mean annual rainfall $(>2,500 \mathrm{~mm})$ compared to the Dry $(<1,750 \mathrm{~mm})$ and Intermediate Zones $(1,750-2,500 \mathrm{~mm})$. Although the Wet Zone has no clear dry period, the Dry Zone has a distinct dry season from May - September, and a short dry period is present in the Intermediate Zone. Both Wet and Intermediate Zones are further divided into low-country, mid-country and up-country zones and spread across all elevations above $300 \mathrm{~m}$ and the Dry Zone is defined below $300 \mathrm{~m}$ elevations (only low-country). In the Wet and Intermediate Zones the maximum temperature ranges from $27-35{ }^{\circ} \mathrm{C}$ and $22-35{ }^{\circ} \mathrm{C}$, respectively. In the Dry Zone it ranges from $29-38^{\circ} \mathrm{C}$ (Department of Agriculture, 2006).

\section{Study animals and sample collection}

A cross sectional, island-wide collection of ticks infesting goats (C. a. hircus) was carried out covering the Dry, Intermediate and Wet Zones of Sri Lanka from June 2011 to May 2013. The collection was done in domestic, semidomestic and farm goats belonging to various breeds including, Sri Lankan Boer, Beetal, Kottukachchiya, Jamunapari, Sannan and their cross breeds. Sampling was done on kids and adult male and female goats. Ticks were collected from selected sites in each district according to the distribution of goats using an adaptive sampling technique. Only the goats with tick infestation were sampled and if the captured individual from the herd did not show any tick infestation, that animal was released and not included as sampled. Farms or animals that had a history of recent (one month prior to the visit) application of acaricides prior to sampling were not visited. For each district at least three sites were selected including both rural and urban areas. For each site, a minimum of seven goats were sampled. If the tick abundance was very low ( $<5$ ticks per host) more sampling sites and more individuals were selected per district. All the ticks on a goat were removed if the infestation is low and 100 ticks were collected from heavily infested animals from all the attachment sites in the body. Sampling was done twice a month during dry periods when the tick abundance was high, and each sampling site was visited only once. 
The attachment site of the tick was noted when the tick was removed as, around eye, face, ear (dorsal, ventral sides), ear canal, legs (hind), body (dorsal, ventral and lateral areas of the trunk), neck, tail region, and groins. Only the ticks that were attached to the host and those who were feeding (engorged) were collected. The ticks were located by visual appraisal and by running the hand across the body. Ticks on both sides of the goats were removed using a thin-tipped pair of tweezers without damaging the mouth parts and were preserved in $70 \%$ ethanol. Intensity of the infestation in each host was recorded as low $(<10$ ticks $)$, medium $(<20)$ and high $(20<)$. Samples were brought to the laboratory and the species, sex and life stages were identified morphologically using a stereoscopic dissecting microscope, and standard keys and references (Trapido et al., 1964; Seneviratne, 1965). Uncertain specimens (different life stages of Haemaphysalis intermedia and $H$. bispinosa) were sent to the Institute of Arthropodology and Parasitology (IAP), University of Georgia, USA, for confirmation of identification. The data obtained from the study were expressed as percentages, and the male to female ratios of different tick species were analysed by using a chisquare test. Preference of attachment sites were analysed only for the five most common tick species.

\section{RESULTS}

Of the 25 districts in the country, ticks were collected from 22 districts (seven districts in the Dry Zone; nine districts in the Wet Zone and six districts in the Intermediate Zone) and a total of 2,628 ticks were collected from 740 goats. Eight species of ticks belonging to the two genera Haemaphysalis and Rhipicephalus (Family Ixodidae) were recorded (Table 1; Figure 1). The two most common species in the overall collection were Haemaphysalis intermedia $(\mathrm{n}=1157,44.0 \%)$ followed by H. bispinosa
( $\mathrm{n}=1151,43.8 \%$; Table 1). Haemaphysalis intermedia was dominant in the Dry Zone (85.4\%; Table 1) and was found in the other two zones as well. However, $H$. bispinosa was the most common goat tick in the Wet

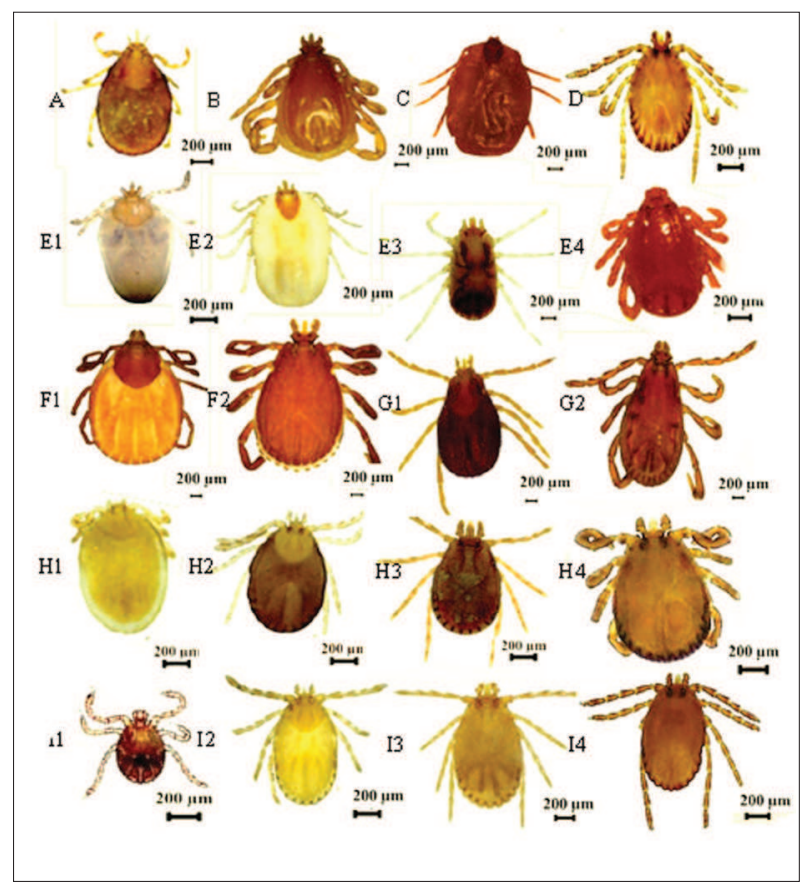

Figure 1: Tick species and their different stages collected from goats in the Wet, Intermediate and Dry Zones of Sri Lanka. A) Rhipicephalus haemaphysaloides nymph; B) R. turanicus male; C) $R$. annulatus female; D) Haemaphysalis cuspidata male; E) $R$. microplus E1) Larvae, E2) Nymph, E3) Female, E4) Male; F) R. Haemaphysaloides F1) Female, F2) Male; G) $R$. sanguineus G1) Female, G2) Male; H) H. intermedia H1) Larvae, H2) Nymph, H3) Female, H4) Male; I) H. bispinosa I1) Larvae, I2) Nymph, I3) Female, I4) Male

Table 1: Distribution of tick species in the Wet, Intermediate and Dry Zones $(\mathrm{N}=2,628)$

\begin{tabular}{lrrrr}
\hline \multirow{2}{*}{ Tick species } & \multicolumn{4}{c}{ Number of ticks (\%) } \\
& Wet Zone & Intermediate & Dry Zone & \multicolumn{1}{c}{ Total } \\
\hline Haemaphysalis intermedia & $260(25.0)$ & $142(20.1)$ & $755(85.4)$ & $1157(44.0)$ \\
H. bispinosa & $656(63.1)$ & $495(70.2)$ & 0.0 & $1151(43.8)$ \\
H. cuspidate & $1(0.1)$ & $1(0.1)$ & $2(0.2)$ & $4(0.2)$ \\
Rhipicephalus sanguineus & $39(3.8)$ & $16(2.3)$ & 0.0 & $55(2.1)$ \\
R. haemaphysaloides & $24(2.3)$ & $35(5.0)$ & $98(11.1)$ & $157(6.0)$ \\
R. turanicus & 0 & 0 & $8(0.9)$ & $8(0.3)$ \\
R. annulatus & 0 & 0 & $8(0.9)$ & $8(0.3)$ \\
R. microplus & $59(5.7)$ & $16(2.3)$ & $13(1.5)$ & $88(3.3)$ \\
\hline Total & 1,039 & 705 & 884 & 2,628 \\
\hline
\end{tabular}

( $\mathrm{N}=$ total number of ticks) 


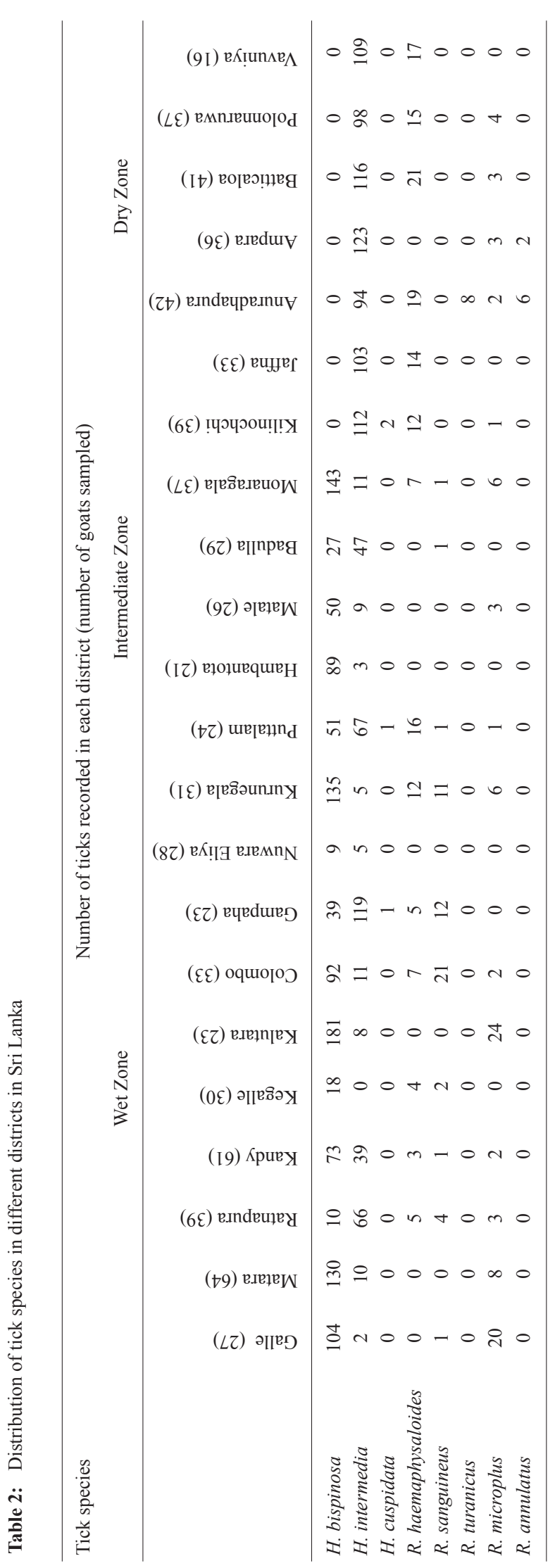

and Intermediate Zones, except in Ratnapura, Gampaha, Puttalam and Badulla Districts (Table 2). In these exceptions $H$. intermedia was the dominating species. Haemaphysalis bispinosa was not reported from the Dry Zone. Rhipicephalus sanguineus was restricted only to the Wet and Intermediate Zones whereas $R$. annulatus and $R$. turanicus were restricted only to the Dry Zone. Rhipicephalus turanicus was found only in Anuradhapura District. Of the eight tick species found on goats, two species, $R$. turanicus and $R$. microplus were new host records for Sri Lanka.

The two major tick species in the collection, $H$. intermedia and $H$. bispinosa showed a wide distribution within the country and within the Wet and Intermediate Zones, respectively (Figure 2). Haemaphysalis intermedia was recorded in every district except Kegalle. In the areas of Hambantota District belonging to the Intermediate Zone, a higher number of H. bispinosa was recorded (Table 2). Colombo District had a high $R$. sanguineus infestation compared to the other areas. Rhipicephalus haemaphysaloides was found in every district in the Dry Zone except Ampara and $R$. microplus was high in Kalutara and Galle Districts. Rhipicephalus annulatus was only found in Anuradhapura and Ampara Districts (Table 2). The least common species, H. cuspidata was found in very low numbers with a limited distribution within the Puttalam, Gampaha and Killinochchi districts (Table 2; Figure 2).

Adults formed $70.8 \%$ (males $58.4 \%$; females $41.6 \%$; Table 3 ) of the total tick collection where the nymphs and larvae formed $25.9 \%$ and $3.3 \%$, respectively (Table 3 ). Overall, more male ticks were found than females $\left(\chi^{2}, \mathrm{p}<0.05\right)$ except for $H$. bispinosa where there was no significant difference $\left(\chi^{2}, \mathrm{p}>0.05\right.$; Table 3$)$. The larval stages of $R$. haemaphysaloides and $R$. sanguineus were not recorded. Only one nymph of $R$. haemaphysaloides was recorded in the Intermediate Zone (Kurunegala District), which could be an accidental occurrence. All the life stages of $H$. bispinosa, $H$. intermedia and $R$. microplus were recorded with a few larval stages.

Most of the tick species preferred the anterior side of the host than the posterior side with one exception, R. microplus (Table 4). In general, the most preferred sites were dorsal and ventral sides of the ear of the goat. Among the most common tick species, Haemaphysalis species were found attached to the dorsal side of the ears, while Rhipicephalus species (except $R$. microplus) preferred the ventral sides of the ear. 


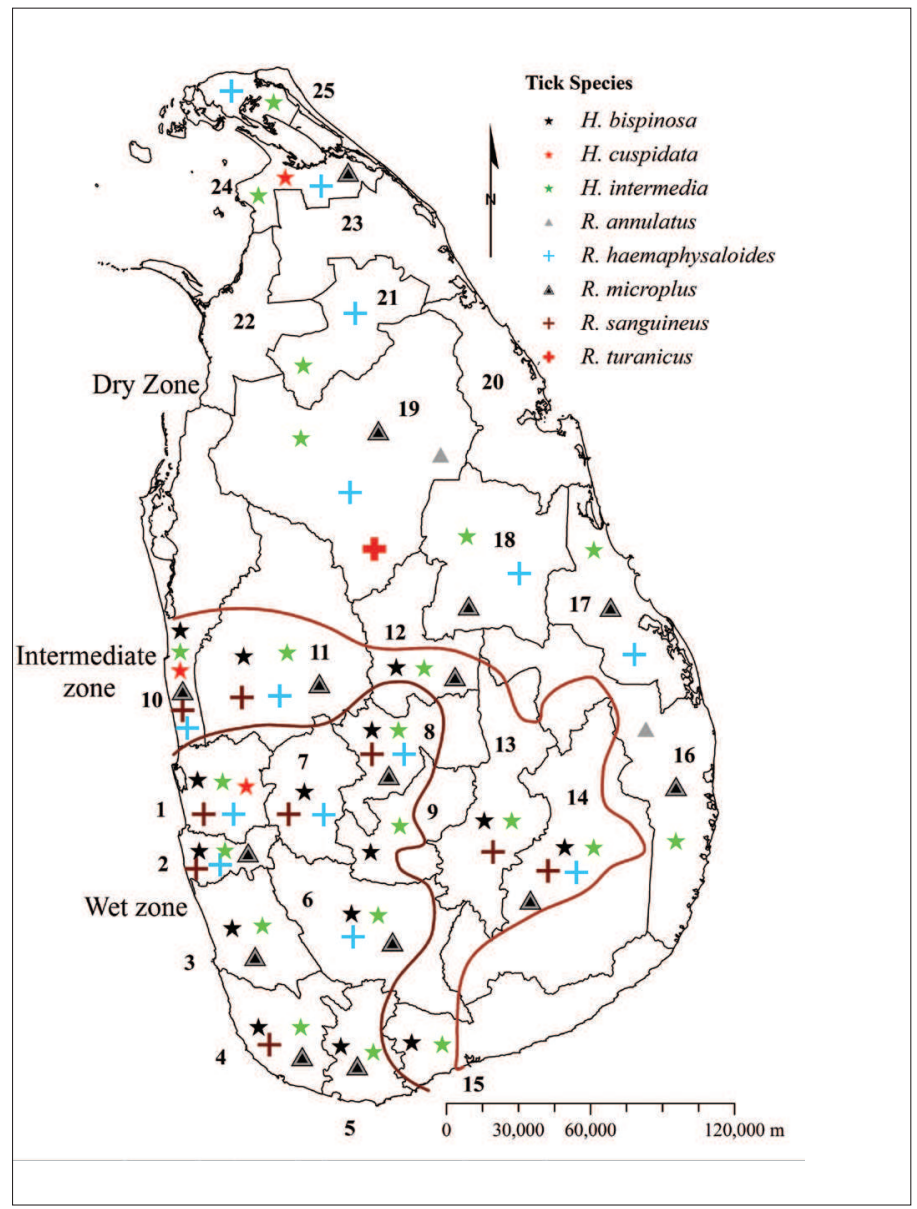

Figure 2: Distribution of goat tick species in the three agro-climatic zones of Sri Lanka. Wet Zone; 1) Gampaha; 2) Colombo; 3) Kalutara; 4) Galle; 5) Matara; 6) Rathnapura; 7) Kegalle; 8) Kandy and 9) Nuwara Eliya. Intermediate Zone; 10) Puttalam; 11) Kurunegala; 12) Matale; 13) Badulla; 14) Monaragala and 15) Hambantota. Dry Zone; 16) Ampara; 17) Batticaloa; 18) Polonnaruwa; 19) Anuradhapura; 21) Vavuniya; 24) Kilinochchi and 25) Jaffna. Districts that were not sampled; 20) Trincomalee; 22) Mannar and 24) Mullativu

Table 3: Distribution of different life stages of goat ticks in the Wet, Intermediate and Dry Zones

\begin{tabular}{lrrrrr}
\hline Tick Species & \multicolumn{3}{c}{ Adults n (\%) } & Nymphs & Larvae \\
& \multicolumn{1}{r}{ Male } & \multicolumn{1}{c}{ Female } & \multicolumn{1}{c}{ Total } & $\mathrm{n}(\%)$ & $\mathrm{n}(\%)$ \\
\hline H. bispinosa & $311(11.8)$ & $344(13.1)$ & $655(24.9)$ & $427(16.3)$ & $69(2.5)$ \\
H. intermedia & $606(23.1 *)$ & $313(11.8 *)$ & $919(34.9)$ & $223(8.4)$ & $15(0.6)$ \\
H. cuspidata & $4(0.2)$ & $0(0.0)$ & $4(0.2)$ & $0(0.0)$ & $0(0.0)$ \\
R. haemaphysaloides & $92(3.5 *)$ & $64(2.4 *)$ & $156(5.9)$ & $1(0.04)$ & $0(0.0)$ \\
R. sanguineus & $48(1.8 *)$ & $7(0.3 *)$ & $55(2.1)$ & $0(0.0)$ & $0(0.0)$ \\
R. turanicus & $5(0.3)$ & $3(0.2)$ & $8(0.5)$ & $0(0.0)$ & $0(0.0)$ \\
R. microplus & $17(0.7 *)$ & $33(1.3 *)$ & $50(2.0)$ & $32(1.2)$ & $6(0.2)$ \\
R. annulatus & $0(0.0)$ & $8(0.3)$ & $8(0.3)$ & $0(0.0)$ & $0(0.0)$ \\
\hline Total & $1083(58.4)$ & $772(41.6)$ & $1855(70.8)$ & $683(25.9)$ & $90(3.3)$ \\
\hline
\end{tabular}

* Statistically significant $\left(\chi^{2}, \mathrm{p}<0.05\right)(\mathrm{n}=$ total number of ticks $)$ 


\section{DISCUSSION}

The results of this study show that the goats in Sri Lanka are infested by eight tick species, namely, Haemaphysalis intermedia, H. bispinosa, H. cuspidata, Rhipicephalus haemaphysaloides, $R$. sanguineus, $R$. microplus, $R$. annulatus and $R$. turanicus. Previously, Seneviratne (1965) reported six species of ticks; $R$. haemaphysaloides, $R$. sanguineus, $R$. annulatus, $H$. bispinosa, $H$. leachi var. indica and Hyalomma marginatum isaaci (Hyalomma isaaci according to current classification) from goats. Later, Halim et al. (1983) recorded Hy. m. isaaci (Hy. isaaci) and R. annulatus along with $H$. intermedia, $R$. haemaphysaloides and $R$. sanguineus in Kotukachchiya Farm in the Dry Zone of Sri Lanka. Recently, Liyanaarachchi et al. (2013) recorded eight tick species including $R$. boophilus (which is not a valid tick name however), $R$. sanguineus, $R$. haemaphysaloides, $H$. bispinosa, $H$. intermedia, H. cuspidata, Amblyomma testudinarium and Haemaphysalis aculeata from farm goats. Compared to these previous records, four species, $H y$. isaaci, $H$. lechi var indica, A. testudinarium and H. aculeata were not found in the present study; instead two new species, which were not previously recorded on goats, namely, $R$. turanicus and $R$. microplus were found.

Halim et al. (1983) reported H. intermedia as the dominant tick species in the Dry Zone, which is consistent with the findings of the present study. However, H. bispinosa was the major tick species that infested goats in both Wet and Intermediate Zones. Haemaphysalis intermedia seems to prefer dry climates, while $H$. bispinosa prefers wet climates. Moreover, among the lesser species, $R$. sanguineus was not recorded in the Dry Zone, while $R$. annulatus and $R$. turanicus were reported only from the Dry Zone. This shows that depending on the agro-climatic region, the dominant species and the distribution of tick species varied. However, Seneviratne (1965) has recorded H. bispinosa infesting goats throughout the country from Jaffna to the highest elevation in Nuwara Eliya as well as a wide range of domestic and wild animals. Although Senevitatne (1965) recorded $H$. leachi var. indica in goats, none of the studies carried out later (Halim et al., 1983; Liyanaarachchi et al., 2013) or the present study record this tick species on goats.

Haemaphysalis ticks, specially $H$. bispinosa has a vast range of geographic distribution in the Oriental Region (Trapido et al., 1964). A recent survey carried out in Bangladesh with sub-tropical monsoon climate (Islam et al., 2006) and Tamil Nadu State in India with tropical climate and little seasonal variations (Soundararajan et al., 2014) shows that $H$. bispinosa parasitise more goats than any other domesticated animal and that it is widely distributed. In the present study $H$. bispinosa was the most common species in the Wet and Intermediate Zones of Sri Lanka. In general, adults of this tick species parasitise wild and domestic artiodactyls, but can also infest carnivores and the immature ticks can be found on birds (Kaul et al., 1979; Hoogstraal \& Kim, 1985). In Sri Lanka $H$. intermedia was the most widespread and most abundant goat tick species. However, it has a restricted geographic distribution in the world where it has been recorded from the southern parts of India and Sri Lanka (Trapido et al., 1964). Principal hosts of $H$. intermedia are livestock, mainly sheep and goats and the immature ticks mainly feed on birds (Kaul et al., 1979; Jeevanandam, 1991).

Four species of the genus Rhipicephalus were recorded during the study, where infections of $R$. sanguineus were found only in the Wet and Intermediate Zones. Rhipicephalus sanguineus is a three-host species and mainly parasitises domestic dog, on which all the stages feed. It also parasitises other carnivores and ungulates (Kolonin, 2009). Rhipicephalus sanguineus is the common dog tick in Sri Lanka (Unpublished observations). The presence of $R$. sanguineus on goats may be because the dogs mingle in the areas where the goats are reared specially in the Wet Zone. In the Dry Zone, sampling was mostly done in Muslim villages where dogs were less common as household pets. Absence of $R$. sanguineus on goats in the Dry Zone may be due to the absence of mingling of goats with dogs.

Rhipicephalus haemaphysaloides and R. microplus were recorded on goats from all three agro-climatic zones. These two species are the most abundant cattle tick species in Sri Lanka (unpublished data). According to the management practices of livestock in Sri Lanka, cattle and goats are kept in the same farmland or their grazing pasture may overlap. Although goats are known to harbour a large number of immature stages of ticks and a fewer adults (Baker \& Ducasse, 1968; Maclvor \& Horak, 2003), and cattle may harbour larger numbers of both adult and immature ticks (Baker \& Ducasse, 1967), in the present study the majority of $R$. haemaphysaloides were adults while there were some immature stages of $R$. microplus on goats. Rhipicephalus microplus is an invasive tick of European cattle breeds (Leger et al., 2013). Goats are not ideal for the development of $R$. microplus but when the suitable host (cattle) is not present goats can act as the alternative host (Daemon et al., 1998; Nyangiwe \& Horak, 2007). Goats may play 
Table 4: Details of tick attachment sites on the host ${ }^{*}$

\begin{tabular}{|c|c|c|c|c|c|c|c|c|c|c|c|c|}
\hline \multirow[t]{2}{*}{ Tick Species } & \multicolumn{5}{|c|}{ Anterior region $(\%)$} & \multicolumn{4}{|c|}{ Posterior region $(\%)$} & \multirow[b]{2}{*}{ 章 } & \multicolumn{2}{|c|}{ Total $(\%)$} \\
\hline & 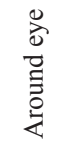 & $\begin{array}{c}\underset{J}{\mathbb{Z}} \\
\text { II }\end{array}$ & 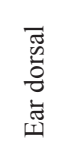 & 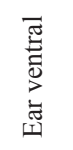 & 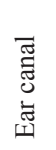 & ర్రి & $\begin{array}{l}\vec{Z} \\
0 \\
0\end{array}$ & $\begin{array}{l}\text { Ù } \\
\ddot{Z}\end{array}$ & $\bar{\Xi}$ & & 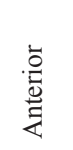 & 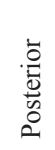 \\
\hline H. bispinosa & 3.3 & 22.1 & 10.3 & 41.7 & 2.0 & 5.6 & 3.7 & 3.5 & 8.1 & 0.2 & 79.1 & 20.9 \\
\hline H. intermedia & 1.3 & 10.9 & 37.0 & 42.7 & 6.1 & 0.3 & 0.2 & 1.9 & 0.0 & 0.0 & 97.8 & 2.2 \\
\hline R. sanguineus & 7.3 & 21.9 & 31.0 & 27.3 & 7.3 & 0.0 & 0.0 & 3.7 & 0.0 & 1.9 & 94.5 & 5.5 \\
\hline R. haemaphysaloides & 18.0 & 14.8 & 48.8 & 13.5 & 2.6 & 0.0 & 0.0 & 0.7 & 2.0 & 0.0 & 97.4 & 2.6 \\
\hline R. microplus & 0.0 & 0.0 & 0.0 & 9.1 & 1.2 & 3.5 & 4.6 & 1.2 & 4.6 & 76.2 & 11.3 & 88.7 \\
\hline Total & 3.2 & 15.9 & 24.4 & 39.2 & 3.9 & 2.8 & 1.9 & 2.5 & 3.9 & 2.8 & 86.5 & 13.6 \\
\hline
\end{tabular}

* Data on the attachment sites of five most common tick species are given

an important role in maintaining infestations of ticks that normally infest cattle, dogs and other domestic animals.

Due to the transport of goats within the country (to farms and abattoirs located in different areas) ticks are introduced into new areas with goats. Once they are introduced into a new area they exploit new host species. The present study reports low infestation levels of $R$. microplus, $R$. turanicus, $H$. cuspidata and $R$. annulatus, which indicate that goats may not be the suitable host. But with time they can evolve associations with their new hosts for successful invasion. For example, $R$. microplus, which invaded cattle in New Caledonia, Australia has adapted to feed on rusa deer (Cervus timorensis) as a new host (Leger et al., 2013). These two populations (deer feeding and cattle feeding) have evolved into two genetically different groups as cattle-adapted and deer-adapted populations within a few tick generations (de Meeus et al. 2010; Leger et al., 2013; Pfaffle et al., 2013).

Among the adults, significantly more males (58.4\%) were present than females $(41.6 \%)$. The presence of more males has been reported in many studies (Halim et al., 1983; Foldvan \& Farkas, 2005; Dantas-Torres \& Otranto, 2011). Usually males stay for a longer period on the host mating with several females and taking short blood meals, whereas the females drop off to oviposit after their parasitic phase. However, in R. microplus fewer males were recorded. Rhipicephalus microplus males are extremely small compared to their females, so the males can easily be missed during sampling. All the life stages of $H$. bispinosa and $H$. intermedia (multi host ticks) occurred on goats. Only the adults of $R$. sanguineus, a three-host monotropic tick of domestic dog on which all stages usually feed (Dantas-Torres, 2010), is found on goats. When the goats are confined to enclosed sheds with limited space, when considering multi host ticks, completing its life cycle in such environment and finding a different new host could be hard for immature ticks. Therefore the abundance and distribution of ticks with limited movements can greatly be affected by the chances of encounter with a potential host and their population densities (Pfaffle et al., 2013). Migrating hosts with high population densities and their social activities facilitate the dispersion of ticks (tick borne diseases as well) that eventually increases the chance of finding a suitable host. That may be the reason of associating immature ticks more with small mammals, which allow the ticks to reach a suitable large host (Kiffner et al., 2011a; Leger et al., 2013).

Different tick species have different preferred sites of attachment on the host body. Most were found on the anterior parts of the host, specifically dorsal and ventral sides of the ears. However, R. microplus preferred posterior parts of the host. This may be an evolutionary adaptation to reduce the competition with other tick species and at the same time to minimize the host defence mechanisms (Belan \& Bull, 1991; Shaw et al., 2002). Preferred attachment sites are influenced by various factors such as the morphology of the tick (e.g. length of the hypostome), morphology of the host (length of the fur coat), host immune responses, self-grooming, inter-specific interactions, heat dissipating behaviour and length of the feeding phase (Belan \& Bull, 1991; Shaw et al., 2002). Ticks select an area with a good blood supply, minimal host defence, where predators (e.g. birds) cannot easily reach and where they can easily penetrate the skin. They may avoid sites, which 
are accessible for grooming and where the host skin is hard to penetrate (Fourie et al., 1991; Kiffner et al., 2011b) and prefer the dorsal side of the ear, which has a short fur coat. Fur can retain humidity, give a suitable micro habitat and also give protection from predators. The present study reports that $R$. microplus preferred the posterior region of the host, which is consistent with previous records of Daemon et al. (1998) and Latha et al. (2004). This behaviour is important because it will reduce the competition for attachment sites with the dominating species $H$. bispinosa, which preferred the anterior part.

All the tick species reported in this study, except for $R$. microplus and $R$. annulatus were three host ticks where the larvae, nymphs and adults feed on different hosts except $R$. sangenius in which all three stages feed on dog. Most tick infections show transovarian transmission. Ticks with two or three hosts therefore have a higher risk of transmitting tick borne diseases among livestock and humans than one host ticks. Thirty three strains of Ganjam virus has been isolated from Haemaphysalis ticks in India, which caused morbidity and mortality in cross breed goats (Sudeep et al., 2009). The risk of spreading this virus in Sri Lanka is high due to the presence of $H$. bispinosa, $H$. intermedia as dominating tick species. Species of Rhipicephalus act as vectors for Leishmania, Babesia, Ehrlichia and possibly transmit Kyasanur Forest disease virus (Estrada-pena \& Jongejan, 1999; Coutinhoa et al., 2005; Dantas-Torres \& Otranto, 2011). Infectious agents carried by goats are not known in Sri Lanka although many of the species recorded are known to carry many infectious agents elsewhere.

The abundance and distribution of ticks depend upon many factors such as the climate and microclimate (temperature, humidity and wind speed), habitat characteristics (soil temperature, vegetation and direct sunlight), presence of other domestic and wild animals, nature of the host (susceptibility, breed, age and sex) and management practices including the use of acaricides (de Meeus et al. 2010). This study was an island-wide cross sectional survey. A longitudinal study for at least a two-year period in a few locales would determine the seasonal dynamics of tick species.

\section{Acknowledgement}

The authors thank all the goat owners and the people who helped in sampling, Dmitry A. Apanaskevich and Sodini Ariyaratne for the identification of ticks and the financial assistance provided by the National Research Council (Grant 11-44).

\section{REFERENCES}

1. Aktas M., Altay K. \& Dumanli N. (2006). A molecular survey of bovine Theileria parasites among apparently healthy cattle and with a note on the distribution of ticks in eastern Turkey. Veterinary Parasitology 138: 179 - 185. DOI: http://dx.doi.org/10.1016/j.vetpar.2006.01.052

2. Al-Khalifa S., Khalil G.M. \& Diab M. (2007). A two years study of ticks infesting goats and sheep in Abha, Saudi Arabia. Saudi Journal of Biological Science 14(1): $83-91$.

3. Baker M.K. \& Ducasse F.B.W. (1967). Tick infestation of livestock in Natal. I. the predilection sites and seasonal variations of cattle ticks. Journal of the South African Veterinary Medical Association 38: 447 - 453.

4. Baker M.K. \& Ducasse F.B.W. (1968). Tick infestation of livestock in Natal. the role played by goats as reservoirs of the economically important cattle ticks. Journal of the South African Veterinary Medical Association 39: 55 - 59.

5. Belan I. \& Bull C.M. (1991). Host detection of four Australian tick species. Journal of Parasitology 77(3): $337-340$.

DOI: http://dx.doi.org/10.2307/3283115

6. Bock R., Jackson L. de Vos A. \& Jorgensen W. (2004). Babesiosis of cattle. Parasitology 129: S247 - S269. DOI: http://dx.doi.org/10.1017/S0031182004005190

7. Brown C.G.D. (1990). Control of tropical theileriosis (Theileria annulata infection) of cattle. Parassitologia 32: $23-31$.

8. Coutinhoa M.T.Z., Buenoa L.L., Sterzika A., Fujiwaraa R.T., Botelhoa J.R., Mariab M.D., Genaroa O. \& Linardia P.M. (2005). Participation of Rhipicephalus sanguineus (Acari: Ixodidae) in the epidemiology of canine visceral leishmaniasis. Veterinary Parasitology 128(1-2): $149-155$.

DOI: http://dx.doi.org/10.1016/j.vetpar.2004.11.011

9. Daemon E., Prata M.C.A. \& Faccini J.L.H. (1998). Goats as alternative hosts of Boophilus microplus (Acari: Ixodidae). Brazilian Journal of Veterinary Parasitology 7(2): $123-128$.

10. Dantas-Torres F. (2010). Biology and ecology of the brown dog tick, Rhipicephalus sanguineus. Parasites and Vectors 3: $2-11$.

DOI: http://dx.doi.org/10.1186/1756-3305-3-26

11. Dantas-Torres F. \& Otranto D. (2011). Rhipicephalus sanguineus on dogs: relationships between attachment sites and tick developmental stages. Experimental and Applied Acarology 53: 389 - 397.

DOI: http://dx.doi.org/10.1007/s10493-010-9406-4

12. de Meeus T., Koffi B.B., Barre N., de Garine-Wichatitsky M. \& Chevillon C. (2010). Swift sympatric adaptation of a species of cattle tick to a new deer host in New Caledonia. Infection, Genetics and Evolution 10: 976 - 983. DOI: http://dx.doi.org/10.1016/j.meegid.2010.06.005

13. Department of Agriculture (2006). Climate of Rice Growing 
regions in Sri Lanka. Department of Agriculture, Sri Lanka. Available at http://www.agridept.gov.lk, Accessed 1 November 2014.

14. Department of Animal Production and Health (2012). Annual Report 2012. (pdf). Department of Animal Production and Health, Sri Lanka. Available at http:// www.daph.gov.lk/web/index.php?option $=$ com_content \&v $i e w=$ article $\& i d=84 \&$ Itemid $=122 \&$ lang $=e n$, Accessed 30 October 2014.

15. Estrada-Pena A. \& Jongejan F. (1999). Ticks feeding on humans: a review of records on human-biting Ixodoidea with special reference to pathogen transmission. Experimental and Applied Acarology 23: 685 - 715. DOI: http://dx.doi.org/10.1023/A:1006241108739

16. Foldvan G. \& Farkas R. (2005). Ixodid tick species attaching to dogs in Hungary. Veterinary Parasitology 129: $125-131$.

DOI: http://dx.doi.org/10.1016/j.vetpar.2004.11.032

17. Fourie L.J., Horak I.G. \& Zyl V. (1991). Sites of attachment and intraspecific infestation densities of the brown paralysis tick (Rhipicephalus punctatu) on Angora goats. Experimental and Applied Acarology 12: 243 - 249.

DOI: http://dx.doi.org/10.1007/BF01193470

18. Ghosh S., Azhahianambi P. \& Fuente J. (2006). Control of ticks of ruminants, with special emphasis on livestock farming system in India: present and future possibilities for integrated control. Experimental and Applied Acarology 40: $49-66$.

DOI: http://dx.doi.org/10.1007/s10493-006-9022-5

19. Ghosh S., Bansal G.C., Gupta S.C, Ray D., Khan M.Q., Irshad H., Shahiduzzaman M., Seitzer U. \& Ahmed J.S. (2007). Status of tick distribution in Bangladesh, India and Pakistan. Parasitology Research 101: 207 - 216. DOI: http://dx.doi.org/10.1007/s00436-007-0684-7

20. Halim S.R., Weilgama D.J., Perera P.S.G. \& Fernando S.T. (1983). Ixodidae on goats in the dry zone of Sri Lanka. Sri Lanka Veterinary Journal 31: 14 - 20.

21. Hoogstraal H. \& Kim K.C. (1985). Tick and mammal coevolution, with emphasis on Haemaphysalis. Coevolution of Parasitic Arthropods and Mammals (ed. K.C. Kim), pp. 505 - 568. John Wiley \& Sons, New York, USA.

22. Iqbal A., Siddique F., Mahmood M.S., Shamim A., Zafar T., Rasheed I., Saleem I. \& Ahmad W. (2014). Prevalence and impacts of ectoparasitic fauna infesting goats (Capra hircus) of district Toba Tek Singh, Punjab, Pakistan. Global Veterinaria 12(2): 158 - 164.

23. Islam M.K., Alim M.A., Tsuji N. \& Mondal M.M.H. (2006). An investigation into the distribution, host - preference and population density of Ixodid ticks affecting domestic animals in Bangladesh. Tropical Animal Health Products 38: $485-490$.

DOI: http://dx.doi.org/10.1007/s11250-006-4381-9

24. Jeevanandam T. (1991). Occurrence of mixed populations of sexual and parthenogenetic females in the hard tick Haemaphysalis intermedia. National Academy Science
Letters 14(5): $231-233$.

25. Jongejan F. \& Uilenberg. G. (2004). Global importance of ticks. Parasitology 129: S3 - S14.

DOI: http://dx.doi.org/10.1017/S0031182004005967

26. Kaul H.N., Dhanda V. \& Mishra A.C. (1979). A survey of ixodid ticks in Orissa State, India. Indian Journal of Animal Sciences 49: 707 - 712.

27. Kiffner C., For T., Hagedorn P., Niedrig M. \& Ruhe F. (2011a). Factors affecting patterns of tick parasitism on forest rodents in tick-borne encephalitis risk areas, Germany. Parasitology Research 108: 323 - 335.

DOI: http://dx.doi.org/10.1007/s00436-010-2065-x

28. Kiffner C., Lodige C., Aling M., Vor T. \& Ruhe F. (2011b). Attachment site selection of ticks on roe deer, Capreolus capreolus. Experimental and Applied Acarology 53: 79 $-94$.

DOI: http://dx.doi.org/10.1007/s10493-010-9378-4

29. Kolonin G.V. (2009). Fauna of ixodid ticks of the world. Available at http://www.kolonin.org, Accessed 10 November 2014.

30. Kularatne S.A.M., Edirisinha J.S., Gawarammana I.B., Urakami H., Chenchittikul M. \& Kaiho I. (2003). Emerging rickettsial infections in Sri Lanka: the pattern in the hilly Central Province. Tropical Medicine and International Health 8(9): $803-811$

DOI: Http://dx.doi.org/10.1046/j.1365-3156.2003.01108.x

31. Latha B.R., Aiyasami S.S., Pattabiraman G., Sivaraman T. \& Rajavelu G. (2004). Seasonal activity of ticks on small ruminants in Tamil Nadu State, India. Tropical Animal Health and Production 36: 123 - 133.

DOI: http://dx.doi.org/10.1023/B:TROP.0000012108.425 26.11

32. Leger E., Vourch G., Vial L., Chevillon C. \& McCoy K.D. (2013). Changing distributions of ticks: causes and consequences. Experimental and Applied Acarology 59: $219-244$.

DOI: http://dx.doi.org/10.1007/s10493-012-9615-0

33. Liyanaarachchi D.R., Jinadasa H.R.N., Dilrukshi P.R.M.P. \& Rajapakse R.P.V.J. (2013). Epidemiological Study on ticks in farm animals in selected areas of Sri Lanka. Tropical Agricultural Research 24: 336 - 346.

34. Maclvor K.M. \& Horak I.G. (2003). Ixodid ticks of Angora and Boer goats, grysbok, common duikers, kudus and scrub hares in Valley Bushveld in the Eastern Cape Province. Onderstepoort Journal of Veterinary Research 70: $113-120$.

35. Matos C.D., Sitoe C., Neves L., Nothling J.O. \& Horak I.G. (2009). The comparative prevalence of five Ixodid ticks species infesting cattle and goats in Maputo Province, Mozambique. Onderstepoort Journal of Veterinary Research 76: $201-208$.

DOI: http://dx.doi.org/10.4102/ojvr.v76i2.45

36. Nyangiwe N. \& Horak I.G. (2007). Goats as alternative hosts of cattle ticks. Onderstepoort Journal of Veterinary Research 74: 1 - 7.

DOI: http://dx.doi.org/10.4102/ojvr.v74i1.133

37. Petney T.N., Robbins R.G., Guglielmone A.A., Apanaskevich D.A., Estrada-Pena A., Horak I.G. \& 
Shao R. (2011). A look at the world of ticks. Progress in Parasitology (ed. H. Mehlhorn), chapter 2. Verlag, Berlin Heidelberg, Germany.

DOI: http://dx.doi.org/10.1007/978-3-642-21396-0_15

38. Pfäffle M., Littwin N., Muders S.V. \& Petney T.N. (2013). The ecology of tick-borne diseases. International Journal of Parasitology 43: 1059 - 1077.

DOI: http://dx.doi.org/10.1016/j.ijpara.2013.06.009

39. Premaratna R., Loftis A.D., Chandrasena T.G.A.N., Dasch G.A. \& de Silva H.J. (2008). Rickettsial infections and their clinical presentation in the Western Province of Sri Lanka: a hospital- based study. International Journal of Infectious Diseases 12: 198 - 202.

DOI: http://dx.doi.org/10.1016/j.ijid.2007.06.009

40. Rony S.A., Mondal M.M.H., Isham M.A. \& Begum N. (2010). Prevalence of ectoparasites in goats at Gazipur in Bangladesh. International Journal of Biological Research 2(9): $19-24$.

41. Sajid S.M., Iqbal Z., Khan M.N. \& Muhammad G. (2008). Point prevalence of hard ticks (ixodids) infesting domestic ruminants of lower Punjab, Pakistan. International Journal of Agriculture and Biology 10: 349 - 351 .

42. Seneviratne P. (1965). The Ixodidae (ticks) of Ceylon, part II and III. Ceylon Veterinary Journal 13(2): $28-45$.
43. Shaw M.T., Keesing F., McGrail R. \& Ostfeld R. (2002). Factors influencing the distribution of larval blacklegged ticks on rodent hosts. American Journal of Tropical Medicine and Hygiene 68(4): 447 - 452.

44. Sivakumar T. et al. (11 authors) (2012). A PCR-based survey of selected Babesia and Theileria parasites in cattle in Sri Lanka. Veterinary Parasitology 190(1 - 2): $263-267$.

45. Soundararajan C., Latha B.R. \& Pandian S.S. (2014). Prevalence of tick infestation in goats under different system of management. International Journal of Agricultural Science and Veterinary Medicine 2: 2.

46. Sudeep A.B., Jadi R.S. \& Mishra A.C. (2009). Ganjam virus. Indian Journal of Medical Research 130: 514 - 519.

47. Trapido M., Varma M.G.R., Rajagopalan P.K., Singh K.R.P. \& Rebelio M.J.A. (1964). Guide to the identification of all stages of all Haemaphysalis ticks of South India. Bulletin of Entomological Research 55: 249 - 270. DOI: http://dx.doi.org/10.1017/S0007485300049439

48. Uilenberg G. (1999). Importance of ticks and tick-borne diseases of domestic ruminants in Southern Europe. Parasitologia 1: 107 - 109.

49. Yin H. \& Luo H. (2007). Ticks of small ruminants in China. Parasitology Research 101: S187 - S189. DOI: http://dx.doi.org/10.1007/s00436-007-0688-3 